\title{
MEMÓRIAS DA ESCOLA: ACERVO DO LIAME (LABORATÓRIO DE INFORMAÇÃO, ARQUIVO E MEMÓRIA DA EDUCAÇÃO)
}

\author{
Maria Apparecida Franco Pereira \\ Universidade Católica de Santos \\ cidaunisantos@gmail.com \\ Gabriela Cordeiro Santos \\ Universidade Católica de Santos \\ gabrielacordeiro44@gmail.com
}

O Laboratório de Informação, Arquivo e Memória da Educação (LIAME), foi instituído em 2006, pelo Programa de Pós-graduação em Educação da Universidade Católica de Santos, Brasil. O objetivo dessa comunicação é apresentar as práticas escolares investigadas na Baixada Santista, e suas linhas de pesquisa no âmbito da cultura escolar: a) história das instituições escolares; b) e intelectuais nela atuantes e c) topologia da cultura. Seu acervo consta de biografias, autobiografias, iconografias, documentos manuscritos e impressos e exemplares de materialidade escolar. A metodologia utilizada é a histórico-documental, tendo como referência teórica os conceitos de Escolano Benito e Antonio Viñao. Pode-se afirmar que o LIAME está contribuindo para o levantamento das instituições educativas, evidenciando sua arquitetura, e materialidade escolar, arquivando inúmeros acervos de educadores.

\section{INTRODUÇÃO}

No Brasil, desde os anos de 1990, assuntos sobre arquivos escolares vêm propiciando acalorados debates, atrelados às questões sobre preservação, gestão documental, princípios de acesso e pesquisa. Esses debates são alimentados principalmente por pesquisadores, historiadores da educação e interessados, que idealizam e criam arquivos escolares, certificando que esses são locais de memória (GONÇALVES, 2009, p. 2; PERES, 2019).

Se levarmos em consideração que a escola é um espaço que propicia diversas memórias e que estas se constituem coletivamente e de diversas maneiras, os arquivos escolares são criados com o propósito de salvaguardar essas memórias, sendo constituídos, deste modo, pelos documentos produzidos e deixados pelo trabalho de professores, alunos e administração escolar como um todo, ajudando na compreensão do processo de escolarização de determinado local (NUNES, 1993). Arquivos escolares são criados na intenção de resgatar as memórias da escola, revelando todo o seu valor histórico e social (NORA, 1993). 
Pautados em uma perspectiva de documento e de objeto evidenciados na Nova História, são considerados desde livros didáticos, cadernos de matrículas, atas de reuniões escolares, jornais estudantis, álbuns de fotografias, até atividades e cadernos escolares, documentos que constituem o cotidiano escolar, relevando todo um universo marcado por suas historicidades e subjetividades (NUNES, 2003, p. 8). Desse modo, todos esses documentos são considerados “objetos-pegadas", evidenciando a "caixa-preta" da escola, que são descobertas pela intervenção de pesquisadores e historiadores. Nas palavras de Agustín Escolano Benito:

La cultura material de la escuela es una especie de registro objetivo de la cultura empírica de las instituciones educativas, distinta de la académica y de la política. Élla puede ser valorada como es el exponente visible, y tras su lectura el efecto interpretado, de los signos y de los significados que exhiben los llamados objetos-huella, así como también las representaciones que los replican o acompañan, fuentes intuibles y manejables en las que ha quedado materializada la tradición pedagógica. (2010, p. 14).

Ainda que, esses locais de regaste da memória da escola são de suma relevância, a realidade é que poucos desses lugares se encontram em boas condições. Muitos desses espaços são atingidos pela má preservação, mau acondicionamento de seus documentos, não possuindo patrocínios que ajudem nas despesas necessárias; esses locais são mantidos pela ação voluntária de professores, alunos e interessados que se solidarizam pela causa e passam a contribuir na preservação dessas fontes.

Para explicitar toda a pesquisa realizada sobre o acervo do LIAME, utilizamos:

a) Os estudos de Augustín Escolano Benito (2010) e Antonio Viñao Frago (1995), onde ambos valorizam a cultural escolar, fazendo uma releitura das fontes tradicionais, revelando assim que ela é um registro empírico das instituições educativas, evidenciando a escola por dentro. Assim como ressalta Frago (1995) a cultura escolar possui vários níveis:

El problema radica en que la cultura escolar en cuanto conjunto de aspectos institucionalizados que caracterizan a la escuela como organización, posee varias modalidades o niveles. Podemos, por ejemplo, referirnos a la cultura específica de un establecimiento docente determinado, de un conjunto o tipo de centros por contraste con otros - por ejemplo, las escuelas rurales o las facultades de derecho - , de un área territorial determinada o del mundo académico en general por comparación con otros sectores sociales. (p. 68).

b) O Manual de Trabalhos em Arquivos Escolares (2003), tendo como objetivo apresentar aos professores e alunos de escolas públicas de São Paulo, alguns métodos e 
procedimentos para preservarem e criarem um espaço propício para acondicionar os arquivos escolares.

\section{LIAME COMO UM LOCAL DE MEMÓRIA}

O Laboratório de Informação, Arquivo e Memória da Educação (LIAME), foi idealizado pela professora doutora Maria Apparecida Franco Pereira ${ }^{1}$ e instituído por professores e alunos da Pós-graduação em Educação da Universidade Católica de Santos (UNISANTOS) (São Paulo - Brasil), em 2006. Com o objetivo de salvaguardar as histórias e as memórias das instituições escolares da Baixada Santista (São Paulo - Brasil), o acervo do LIAME, está vinculado a um grupo de pesquisa do mesmo nome, na qual, estão interessados em abordar a história da escolarização em âmbito regional. O LIAME é denominado como um instrumento investigativo que atua na micro-história da Baixada Santista, preocupado em recuperar o Patrimônio Histórico Escolar da região (ESCOLANO BENITO, 2010, p. 17).

Desde a sua constituição, o LIAME foi fundamentado em três eixos temáticos. Esses eixos, ajudam na delimitação e produção de pesquisas que podem ser dirigidas para:

a) História das instituições: estuda as instituições escolares. Os objetivos são fazer levantamento e registrar as instituições escolares na região da Baixada Santista, identificando os objetos de cultura material escolar, situando no tempo e espaço;

b) Educadores e intelectuais: estudar e pesquisar a vida e a obra de membros que atuaram nas instituições escolares da Baixada Santista, produzindo assim biografias;

c) Topologia da cultura: nesse eixo o objeto de estudo é o território urbano onde foram e estão construídas as instituições escolares. Para tal, "os objetivos são localizar e classificar os vestígios da cultura escolar e salientar qual a importância da construção da instituição escolar em determinado local.

\footnotetext{
${ }^{1}$ A professora doutora Maria Apparecida Franco Pereira, atualmente é docente do Programa de Pós-graduação em Educação da Universidade Católica de Santos (SP, Brasil). Dedica-se ao ensino e à pesquisa nas áreas de história e historiografia da educação.
} 
FIGURA 1 - Logotipo do LIAME.

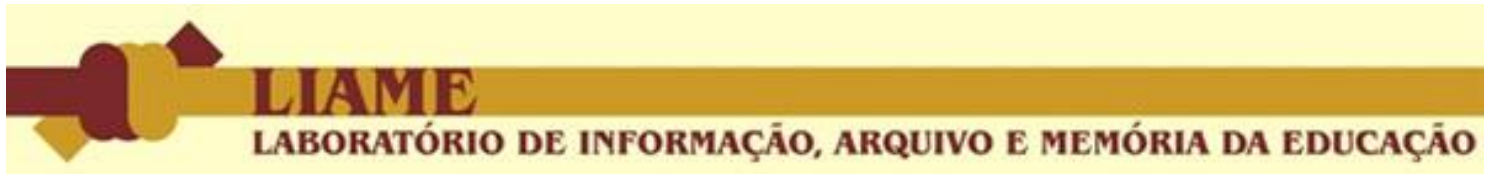

Fonte: Acervo do LIAME.

FIGURA 2 - Folheto explicativo sobre o LIAME e seus três eixos temáticos.

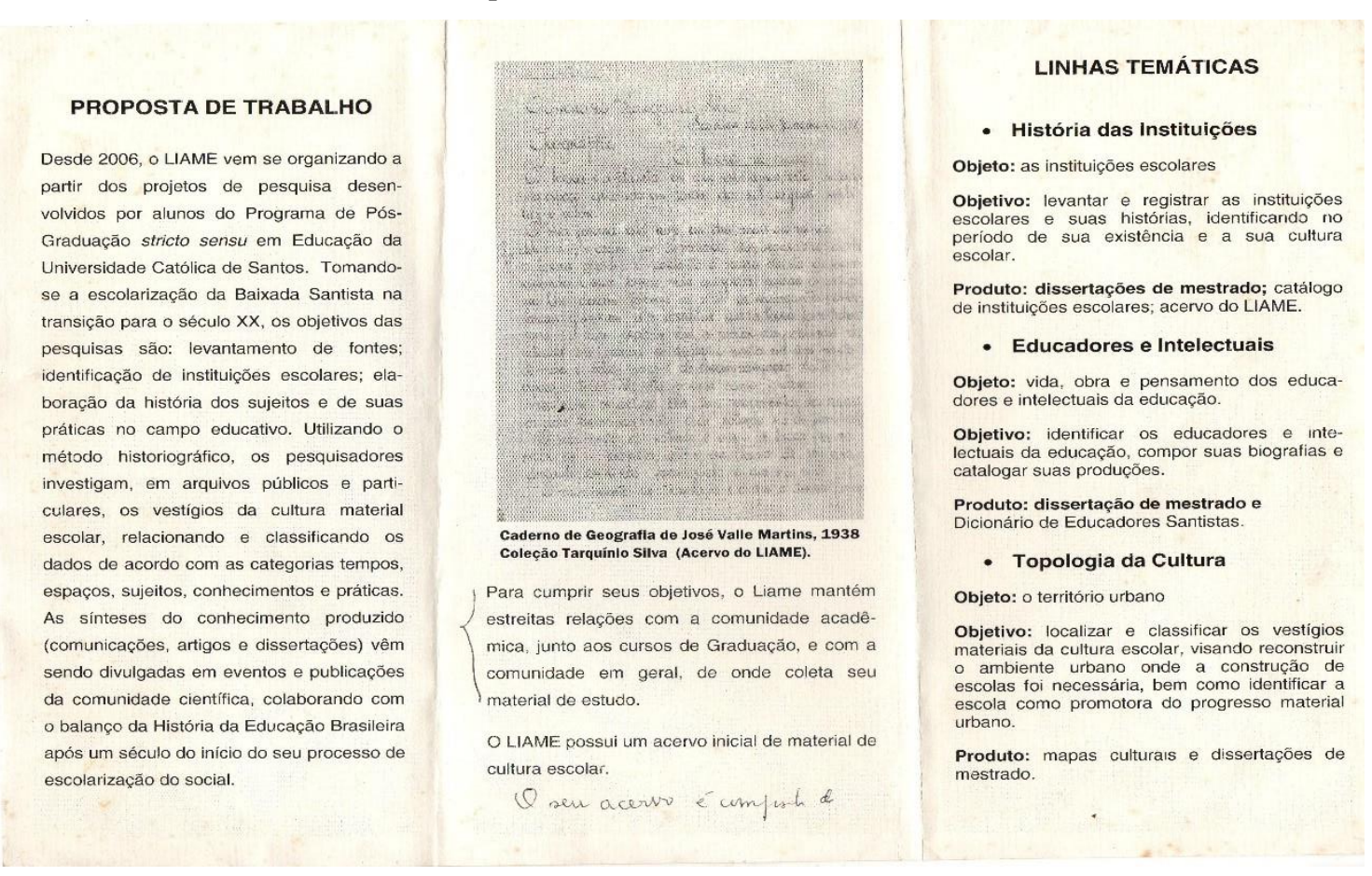

Fonte: Acervo do LIAME.

Além de ser constituído por materiais doados por professores, alunos, familiares e instituições educativas, o acervo do LIAME possui diversos documentos que foram descartados. Muito deles, foram encontrados em porões, lixeiras e locais indevidos para o acondicionamento da documentação. Tomando a perspectiva do Manual de Trabalho em Arquivos Escolares, podemos afirmar que:

Os arquivos escolares são constituídos pelo conjunto de documentos produzidos e recebidos em decorrência das atividades diárias de professores, funcionários, alunos, pais de alunos e todos aqueles que de alguma forma participam do funcionamento da escola. (2003, p. 11).

Deste modo, acervo está atrelado a história da escolarização da Baixada Santista, sobretudo entre a segunda metade do século XIX e meados do século XX e XXI. Podemos encontrar em seu acervo: livros didáticos, cadernos, atas de reuniões escolares, jornais, folhetos, 
revistas acadêmicas sobre educação, gravações de entrevistas, fotos, álbuns de fotografias de alunos e escolas, gravuras, medalhas, apagadores de lousa, tinteiros etc. Como exemplo, podemos citar também os arquivos particulares: como o de Pe. Waldemar Valle Martins (19262004), professor e o primeiro reitor da Universidade Católica de Santos, e o acervo pessoal de Maria Lindomar Martins Vale, professora de Língua Portuguesa e Latim. Com essas fontes materiais e documentais o acervo do LIAME subsidia projetos de pesquisas, dissertações de mestrado, teses de doutorado, biografias, artigos e projetos de Iniciação Científica.

A gestão documental e sua preservação, se dá por meio de trabalho voluntário de professores e alunos da Universidade Católica de Santos ou por professores da rede municipal de Santos e arquitetos. De modo geral, além de ajudarem no acervo, muitos participam do grupo de pesquisa, trazendo temas e debates que ajudam e incorporam no processo de visibilidade e preservação documental do acervo.

FIGURA 3 - Apresentação de alunos da Escola Canadá - Santos, SP.

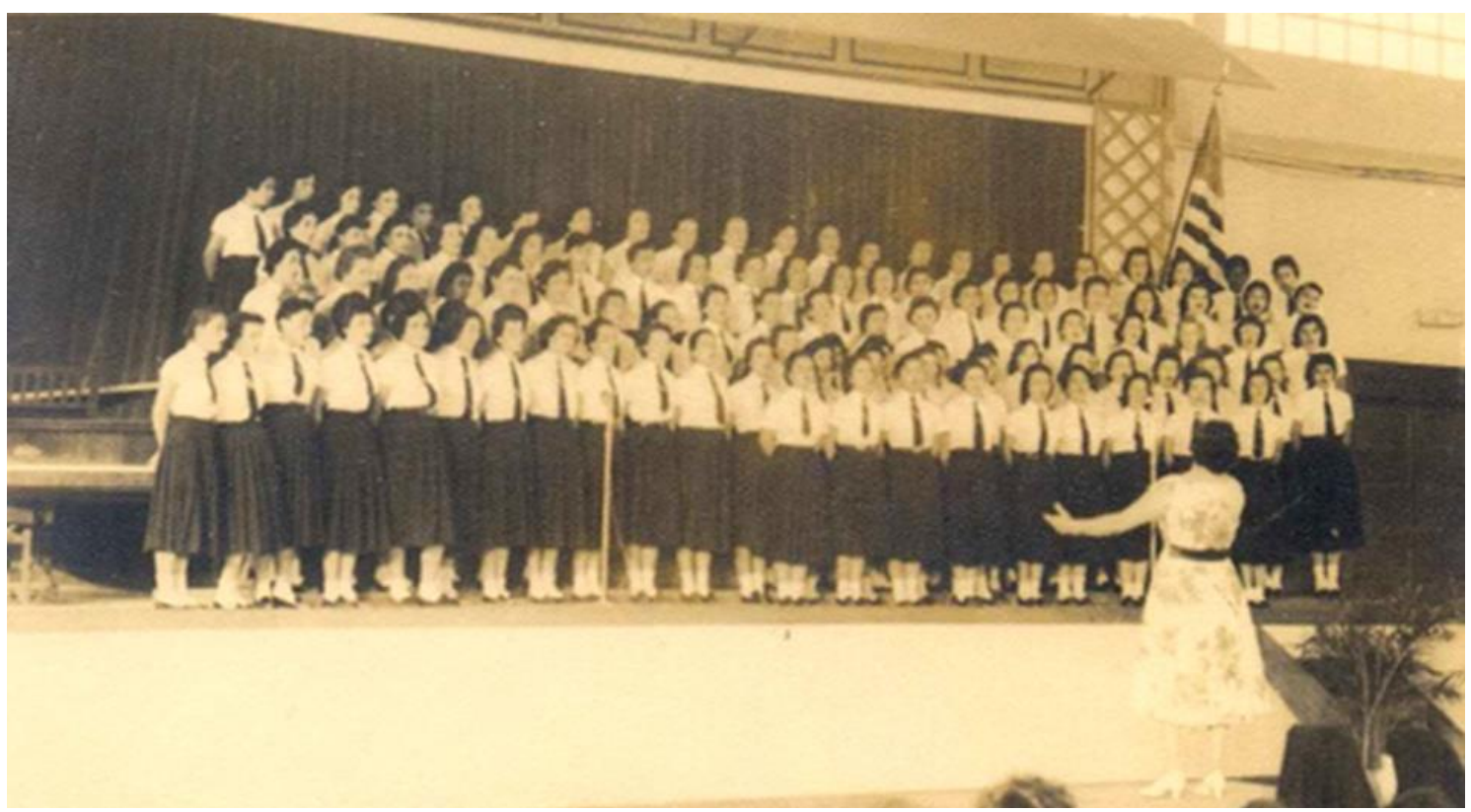

Fonte: Acervo do LIAME. 
FIGURA 4: Escola Técnica de Comércio do Colégio Santista - Técnicos em Contabilidade de 1957.

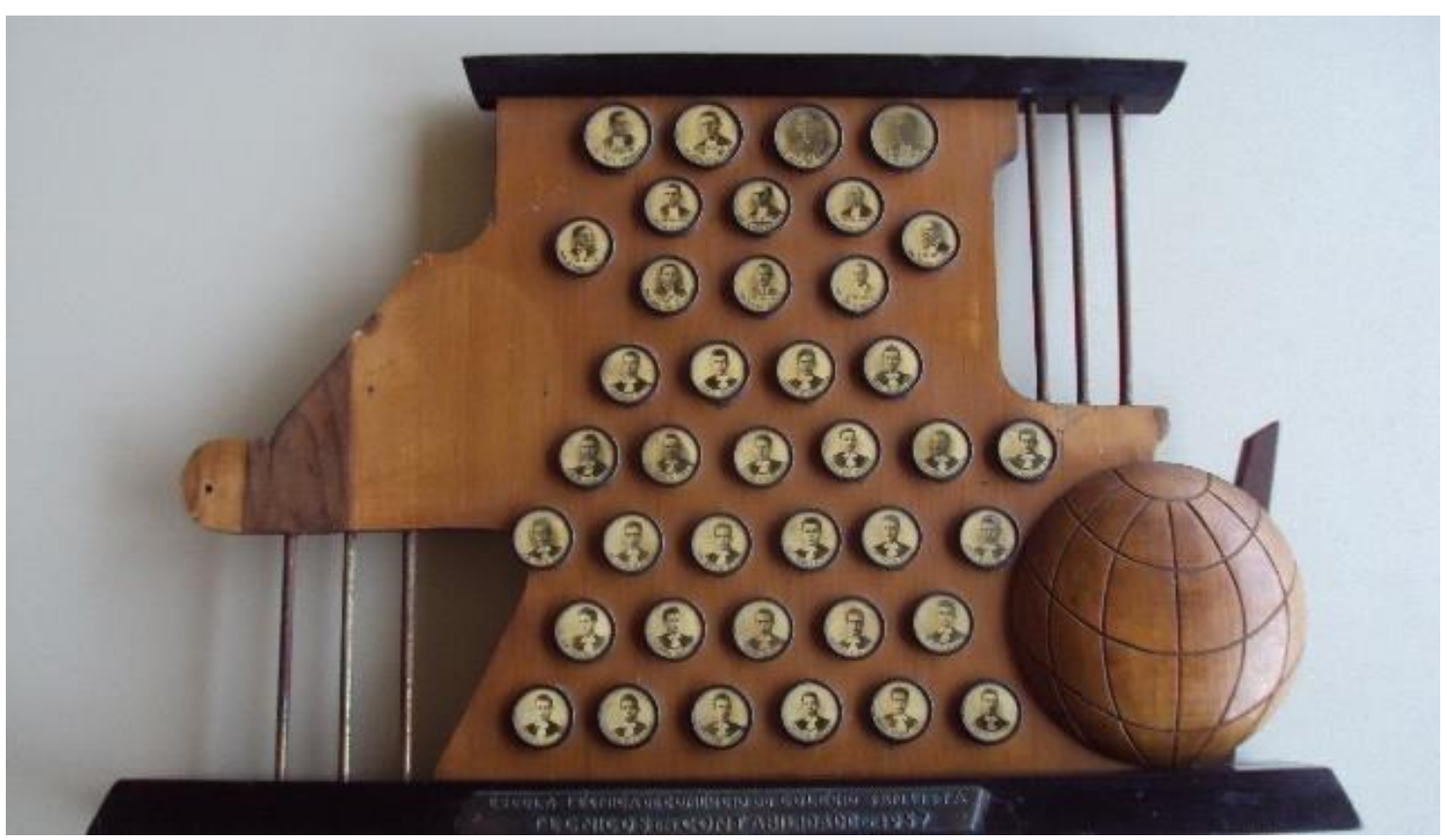

Fonte: Acervo do LIAME.

Além disso, o LIAME procura conscientizar sobre o quanto é importante preservar o patrimônio escolar, dialogando com a comunidade geral e acadêmica. Esse contato se mantém, por meio de eventos e exposições que ocorrem nos pátios da Universidade Católica de Santos. Outra forma de diálogo, que ajuda na divulgação e visibilidade do acervo é a participação em eventos científicos. Levar o LIAME para esses locais e evidenciar sua importância para a contribuição de pesquisas na área de história e historiografia da educação, foi possível a partir de um levantamento documental e bibliográfico, realizado durante o período da Iniciação Científica. Por exemplo, em 2018 apresentamos este projeto, que procurava evidenciar a riqueza de documentos que o acervo comporta. A exposição foi realizada no XIII Congreso Iberoamericano de Historia de la Educación Latinoamericana - Montevidéu (Uruguai). 
FIGURA 5 - Projeto de Iniciação Científica na exposição do acervo do LIAME na Mostra fotográfica LIAME XIII Cihela (Congreso Iberoamericano de Historia de la Educación Latinoamericana) 2018 Montevideo-

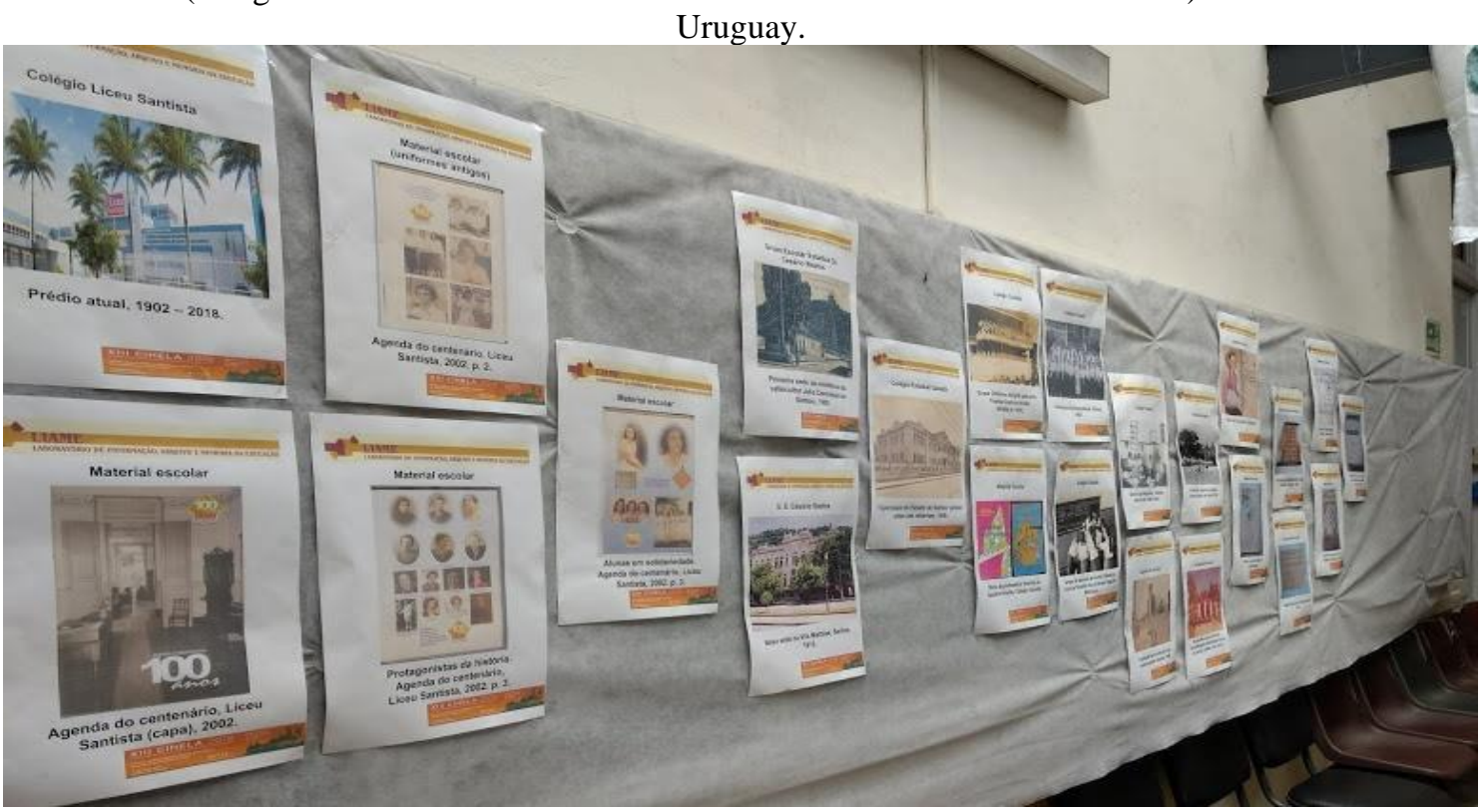

Fonte: Acervo do LIAME.

No levantamento documental, encontramos um CD que contém o website do LIAME. A criação de um site, deu maior visibilidade ao acervo e ao grupo de pesquisa, recebendo comentários positivos de professores e alunos. O intuito do website era disponibilizar o acervo digitalizado do LIAME, onde os internautas podiam apreciar também pesquisas concluídas e em andamento, as participações em eventos, as cartas de aceite das comunicações em eventos científicos, além de encontrarem um breve currículo de cada participante. No e-mail liame@unisantos.br, os navegadores poderiam dar sugestões, tirar dúvidas e receber orientações de como doar documentos e/ou participar do grupo. Na próxima imagem, podemos ver a página inicial do website. Hoje, essa página e endereço está indisponível; em apresentações realizadas na UNISANTOS, alguns discentes se disponibilizaram para ajudar na digitalização de documentos, criação e divulgação de um novo blog. 
Figura 6: Print screen do site do LIAME, que hoje encontra-se desativo.
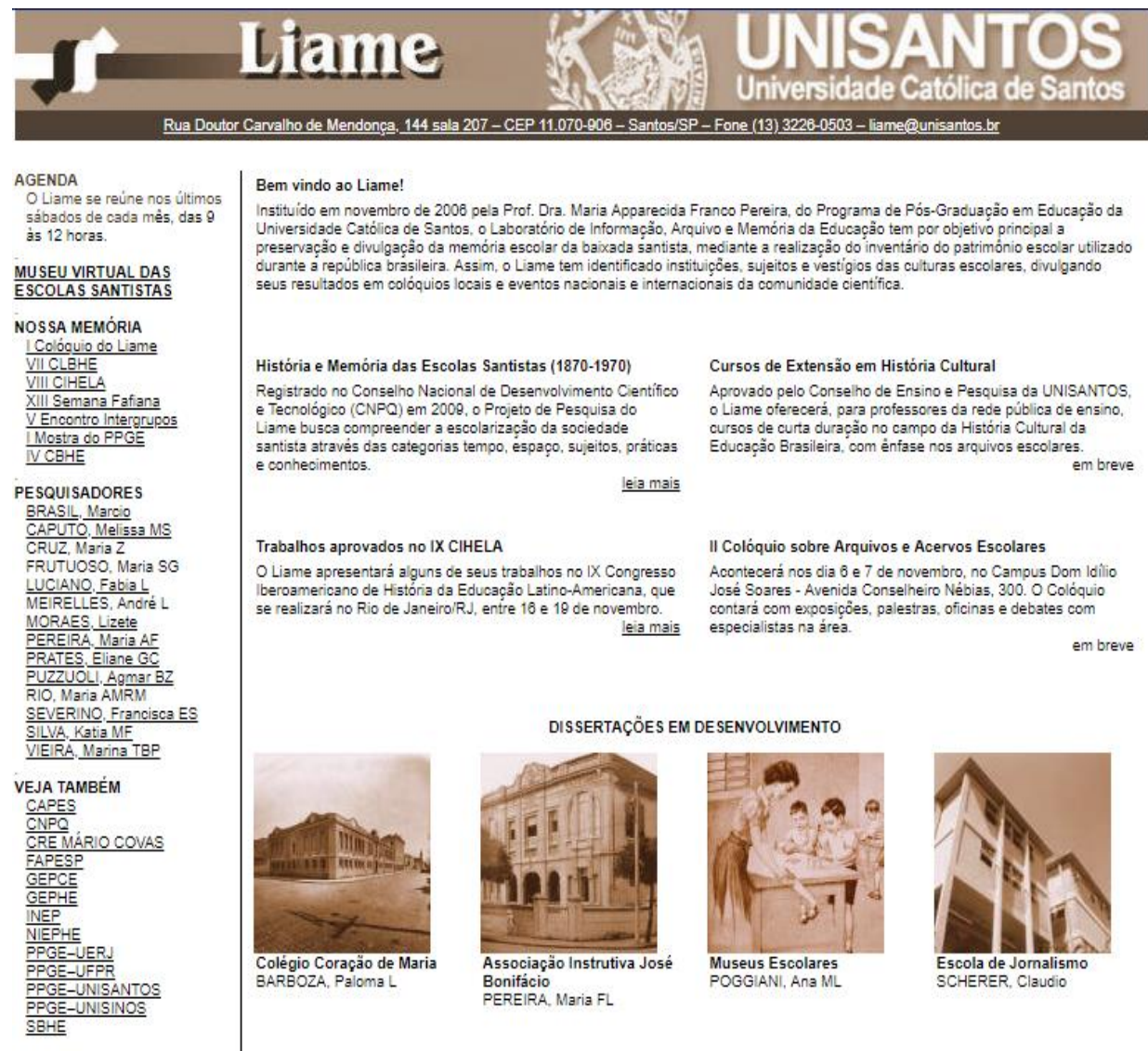

Fonte: Acervo do LIAME.

FIGURA 7 - I Colóquio de Acervos e Arquivos Escolares do LIAME, UNISANTOS, Santos, 2008.

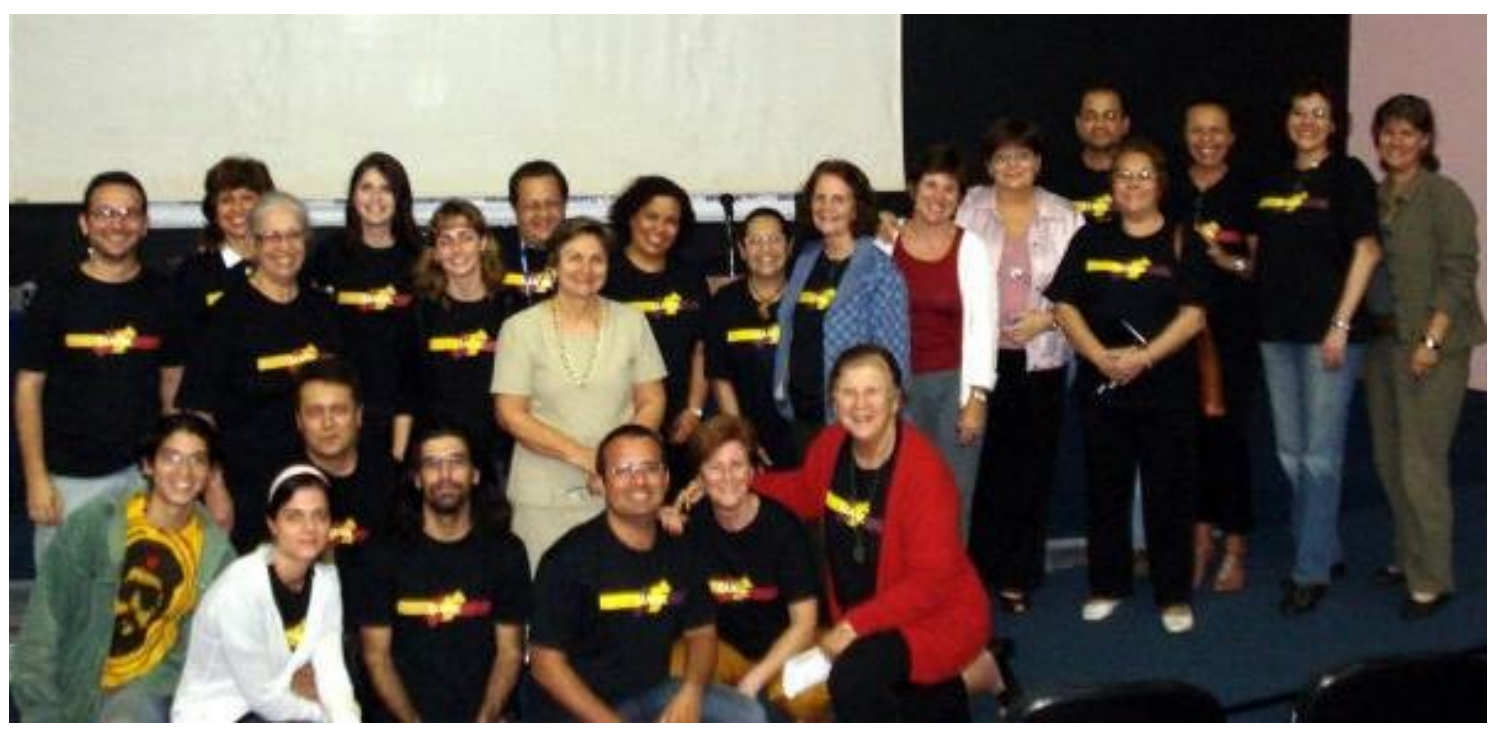

Fonte: Website do LIAME, 2009.

O acervo do LIAME, tem contribuído para a pesquisa na Universidade Católica de Santos, trabalhando na linha de história e historiografia da educação, na Pós-Graduação em 
Educação, na graduação, nos cursos de filosofia, pedagogia e sobretudo história. Também contribui em pesquisas de Iniciação Científica, esta gerida pelo Instituto de Pesquisas Científicas e Tecnológicas (IPECI) da mesma universidade.

O acervo é acessado por professores, alunos e pesquisadores locais e serviu também como modelo para a criação do Centro de Memória Escolar de Praia Grande 2 . O grupo de pesquisa LIAME, desenvolve principalmente o método histórico documental, utilizando fontes primárias, secundárias e iconográficas. No seu acervo há uma quantidade grande de entrevistas sobre a escola, que foram desenvolvidas na graduação de história.

O LIAME também contribui com seu material para pesquisas fora do grupo, como por exemplo:

- Dissertação de mestrado em história da Pontifícia Universidade Católica (PUC) de São Paulo, intitulada de "Sociedade Emancipadora 27 de Fevereiro: um movimento abolicionista na cidade de Santos - 1886 - 1888; estudada por Vera Lucia Alba Rei Dias;

- Outra contribuição importante seria a dissertação de Nadia Ferreira da Silva: "Um estudo da coordenadoria de educação ambiental de Praia Grande como política de meio ambiente". Sua pesquisa era sobre a Coordenadoria de Educação Ambiental (CEA) em Praia Grande (região metropolitana de Santos, São Paulo), que desenvolve suas atividades a partir do ano letivo de 1997, sendo pioneira na região da Costa da Mata Atlântica, tendo por base projetos que priorizam a educação ambiental.

Citaremos abaixo alguns trabalhos científicos, que usufruíram do acervo do LIAME no âmbito da Universidade Católica de Santos:

Quadro 1 - Trabalhos que utilizaram o acervo do LIAME.

\begin{tabular}{|c|c|}
\hline \multicolumn{2}{|c|}{ EXEMPLOS DE PESQUISAS } \\
\hline DOUTORADO EM EDUCAÇÃO & $\begin{array}{ll}\text { SILVA, Alexander Marques da. } \\
\text { Waldemar Valle Martins e sua relação }\end{array}$ \\
\hline
\end{tabular}

\footnotetext{
${ }^{2}$ O Centro de Memória Escolar de Praia Grande (São Paulo, Brasil), está localizado na Rua Jaú, n. 1.158, Boqueirão. Coordenado pela historiadora Mônica Rodrigues e Silva, este Centro de Memória foi criado com objetivo de realizar pesquisas em história e história da educação na cidade de Praia Grande. Além disso, este realiza atividades com os alunos, professores e a comunidade em geral, trabalhando com temas desde memória, história e educação. No âmbito da pesquisa, tem como público alvo universitários e pesquisadores interessados. O Centro de Memória Escolar de Praia Grande, por meio da "Plataforma do Educador" oferece cursos de capacitação para professores da rede municipal de Praia Grande, abordando diversos temas na área de história e historiografia da educação.
} 
com a Ação Católica em Santos/SP, (em andamento).

SILVA, Rafael da Silva e. A rede educacional japonesa da Baixada Santista e Vale do Ribeira (1908-1945), 2016.

MESTRADO EM EDUCAÇÃO ANCELMO, Muriel Carmo Lameira. Escola Estadual Bento de Abreu: um estudo das representações sobre uma instituição de ensino, 2010.

ALVES, Edson Rossetti. Yza Fava de Oliveira: uma intelectual mediadora à frente do Departamento de História a Universidade Católica de Santos, 2017. BARBOZA, Paloma Lopes. A origem do Colégio Coração de Maria e a relação com o bairro da Vila Nova, 2010.

BARRETO, Marcos Mari. $O$ antigo Ginásio do Estado de Santos (atual Escola Estadual Canadá), 1934-1944: arquitetura e educação, 2020.

BEZERRA, Ronaldo Gueiros. A origem do curso de Filosofia da Universidade Católica de Santos, 2019.

BRAGA, Maisa de Almeida. Escola Estadual Dr. Cesário Bastos: Memórias da Escola e da Cidade, 2008.

BRASIL, Marcio. O Grupo Escolar Visconde de São Leopoldo $e$ a Escolarização de Vila Macuco Durante a Primeira República, 2008.

CAMPOS, Angela Bonard Micci Borges de. O curso normal do Liceu feminino 
Santista: a longa busca pela equipação, 2018.

CAPUTO, Melissa Mendes Serrão.

Eunice Caldas: uma voz feminina no silêncio da história (1879-1967), 2008.

FERREIRA, Silvio Carlos. Escola Nossa

Senhora de Lourdes: pioneirismo na integração de valores sociais e educacionais de crianças e adolescentes enfermos por longo tempo, em Santos, 2005.

POGGIANI, Ana Maria Lourenço. Os museus escolares na primeira metade do século $X X$ : sua importância na educação brasileira, 2011.

VICENTE, Neusa Lopes. Protagonismo Juvenil na Universidade Católica de Santos: Lideranças na faculdade de Direito (1986-1990), 2017.

TRABALHO DE CONCLUSÃO DE ALVES, Edson Rossetti. Santa Maria: a CURSO EM HISTÓRIA história de um bairro em transformação na cidade de Santos e suas instituições, 2014.

AMADO, Daniel Otávio. Ruas, Instituições Judaicas de ensino em Santos, 2017.

CAMPOS, Angela Bonard Micci Borges: Um trono à espera: a educação da princesa dona Isabel Cristina para o terceiro reinado, 2015.

SILVA, Sandra Félix da. Vicente de Carvalho: outras faces do Poeta do mar, 2007. 


\begin{tabular}{|c|c|}
\hline & $\begin{array}{l}\text { VENTURA, Magda Fernandes Garcia. A } \\
\text { Educação em Santos, através do Jornal A } \\
\text { Tribuna (1930-1931), } 2013 .\end{array}$ \\
\hline $\begin{array}{c}\text { TRABALHO DE CONCLUSÃO DE } \\
\text { CURSO EM FILOSOFIA }\end{array}$ & $\begin{array}{l}\text { JACOMELI, Juliana. O feminismo } \\
\text { existencialista de Simone de Beauvoir, } \\
2009 . \\
\text { SANTOS, Tiago. A questão do outro e a } \\
\text { solidariedade na filosofia da libertação } \\
\text { de Enrique Dussel, } 2007 .\end{array}$ \\
\hline $\begin{array}{l}\text { TRABALHO DE CONCLUSÃO DE } \\
\text { CURSO EM PEDAGOGIA }\end{array}$ & $\begin{array}{l}\text { CASTRO, Mirian Farias de. A Educação } \\
\text { da Criança na Visão de Maria } \\
\text { Montessori: aspectos do seu método, } \\
\text { 2014. }\end{array}$ \\
\hline $\begin{array}{l}\text { INICIAÇÃO CIENTÍFICA: } \\
\text { ENSINO MÉDIO }\end{array}$ & $\begin{array}{l}\text { GODOY. Murilo Carvalho Moraes } \\
\text { Harrisbeguer. História e Memória da } \\
\text { Escola Estadual "Primo Ferreira" em } \\
\text { Santos, durante a gestão da Professora } \\
\text { Maricléa Barros, } 2015 . \\
\text { RODRIGUES, Carla Danielle Freitas. } \\
\text { História e Memória da Escola Estadual } \\
\text { "Primo Ferreira” em Santos: revisão } \\
\text { documental de sua origem, } 2017 .\end{array}$ \\
\hline $\begin{array}{c}\text { INICIAÇÃO CIENTÍFICA: } \\
\text { GRADUAÇÃO EM HISTÓRIA }\end{array}$ & $\begin{array}{l}\text { ALVES, Edson Rossetti. Santa Maria: a } \\
\text { história de um bairro localizado na } \\
\text { cidade de Santos, } 2013 . \\
\text { CARMO, Bruno Bortoloto do. Entre } \\
\text { práticas e representações: um estudo de } \\
\text { caso do Código de Posturas de Santos } \\
\text { (1857), } 2011 . \\
\text { GONÇALVES, Anderson Rodrigues. Os } \\
\text { movimentos de cidadania no final do } \\
\text { século XIX em Santos: a escravidão e a } \\
\text { educação popular, 2009. }\end{array}$ \\
\hline
\end{tabular}




\begin{tabular}{|l|l|}
\hline OLIVEIRA, Hanna Carolina de Oliveira. \\
Educação Ambiental na Praia do Góis: \\
um estudo de caso, 2011. \\
PEREIRA, Odair José. Samba: da \\
marginalidade a símbolo nacional, 2011. \\
PEREZ, Adriana de Almeida Bracco. \\
Levantamento histórico das Escolas \\
Operárias ligadas ao Porto de Santos, \\
2015. \\
SANTANA JR. Marciano Gaudêncio. \\
Artigos de Educação no Jornal A \\
Tribuna, na década de 1920, 2009. \\
SANTOS, Gabriela Cordeiro. Arquivo e \\
Memória: História e organização do \\
LIAME, 2018. \\
VENTURA, Magda Fernandes Garcia \\
Ventura. O ensino em Santos a partir do \\
levantamento do jornal A Tribuna nos \\
anos 1930 e 1932, 2011. \\
\end{tabular}

Fonte: Acervo do LIAME.

\section{ALGUMAS CONSIDERAÇÕES}

Além das participações do LIAME em eventos, contribuições em pesquisas fora e dentro da Universidade Católica de Santos, o acervo encontra-se em processo de organização e catalogação. Depois de passar por diferentes locais, hoje o acervo encontra-se no campus D. David Picão ${ }^{3}$. Neste edifício, o LIAME se mantém por ações voluntárias de professores e alunos que se solidarizam com a causa, tendo em mente a importância da preservação do patrimônio educativo. Durante muito tempo por falta de verbas e de patrocínio, o acervo do LIAME permaneceu fechado; o acesso era limitado e os pesquisadores só tinham acesso aos documentos por meio da intervenção da professora doutora Maria Apparecida Franco Pereira. Ela buscava os documentos no acervo e entregava para os alunos nas aulas e encontros no

\footnotetext{
${ }^{3}$ O edifício D. David Picão está localizado na R. Comendador Martins, 296 - Encruzilhada, Santos (SP, Brasil).
} 
espaço da universidade. Hoje o acervo pode ser visitado e consultado, marcando hora com a secretaria da UNISANTOS.

A relevância de manter, preservar e administrar um arquivo como o LIAME, evidencia que esses locais de memórias são de suma importância para a compreensão do processo de escolarização de determinado local. Interessado na recuperação do patrimônio histórico educativo da região da Baixada Santista (SP, Brasil), o LIAME é um daqueles locais que sobrevivem mediante a inúmeras situações que assolam esses guardiões da memória: não recebem o devido cuidado e se mantém por meio do trabalho voluntário. Desse modo, podemos ressaltar algumas questões: como conscientizar sobre a importância da preservação dos arquivos e museus escolares? Como o acervo do LIAME contribui para a historiografia local e brasileira? De fato, essas e outras perguntas possuem sua relevância. Através do acervo do LIAME, podemos refletir sobre as práticas escolares, identificando seus atores e militantes, seus pensamentos, sistematizando assim a história e a memória da educação na Baixada Santista, como também a brasileira.

\section{FONTES}

Acervo do LIAME (Laboratório de Informação, Arquivo e Memória da Educação) - Santos (São Paulo, Brasil).

\section{REFERÊNCIAS}

BONATO, Nailda Marinho da Costa. Os arquivos escolares como fonte para a história da educação. Revista Brasileira de História da Educação, São Paulo, n. 10, p. 193-220, jul./dez. 2005.

CEINCE (Centro Internacional de la Cultura Escolar). Disponível em: http://www.ceince.eu/. Acesso em: 17 jan. 2018.

ESCOLANO BENITO, Agustín. Patrimônio Material de La Escuela e Historia Cultural. Revista Linhas, Florianópolis, v. 11, n. 02, p. 13-28, jul. / dez. 2010.

GONÇALVES, Nadia Gaiofatto. A escola e o arquivo escolar: discutindo possibilidades de interlocução entre atividades de ensino, pesquisa e extensão. In: CONGRESSO BRASILEIRO DE HISTÓRIA DA EDUCAÇÃO, 4., 2006, Goiás. Anais do Congresso Brasileiro de História da Educação: A educação e seus sujeitos na história. Goiás: Sociedade Brasileira de História da 2006.2 Disponível em: http://www.sbhe.org.br/novo/congressos/cbhe4/individuaiscoautorais/eixo07/Nadia\%20Gaiofatto\%20Goncalves\%20-\%20Texto.pdf. Acesso em: 23 fev. 2019. 
GONÇALVES, Nadia Gaiofatto. Organização de arquivos históricos escolares: contribuições para uma discussão necessária. In: CONGRESSO IBEROAMERICANO DE HISTÓRIA DA EDUCAÇÃO LATINO-AMERICANA, 11., 2009, Rio de Janeiro. Anais do Congresso Iberoamericano de História da Educação Latino-americana. Rio de Janeiro, 2009. Disponível em: http://simagestao.com.br/wpcontent/uploads/2016/01/Organiza\%C3\%A7\%C3\%A3o-de-Arquivos-Hist\%C3\%B3ricos-

Escolares.pdf. Acesso em: 19 fev. 2019.

LEITE, Lilian Ianke. Arquivo Morto ou Arquivo Histórico-Educacional: qual o lugar da memória da/na escola? Disponível em: https://educere.bruc.com.br/arquivo/pdf2008/114_55.pdf. Acesso em: 09 maio 2018.

MENEZES, Maria Cristina; SILVA, Eva Cristina Leite da; TEIXEIRA JÚNIOR, Oscar. O arquivo escolar: lugar da memória, lugar da história. Horizontes, São Paulo, n. 1, p. 67-76, jan./jun. 2005.

MERLO, Franciele; KONRAD, Glaucia Vieira Ramos. Documento, história e memória: a importância da preservação do patrimônio documental para o acesso à informação. Informação \& Informação, v. 20, n. 1, p. 26 - 42, mar. 2015. Disponível em: http://www.uel.br/revistas/uel/index.php/informacao/article/view/18705/pdf_43. Acesso em: 21 out. 2018.

NORA, Pierre. Entre memória e história: a problemática dos lugares. Projeto História: Revista do Programa de Estudos Pós-Graduados de História, v. 10, out. 2012. Disponível em: https://revistas.pucsp.br/index.php/revph/article/view/12101/8763. Acesso em: 08 nov. 2018 .

OLIVEIRA, Mariza da Gama Leite de. Arquivos Escolares: fontes para a história da educação. In: CONGRESSO NACIONAL DE EDUCAÇÃO, 11.; 2013, Curitiba. Anais do XI Congresso Nacional de educação: formação para mudanças no contexto da educação: políticas, representações sociais e práticas. Curitiba: EDUCERE, 2013. Disponível em: https://educere.bruc.com.br/arquivo/pdf2013/10233_5809.pdf. Acesso em: 16 abr. 2019.

PEREIRA, Maria Apparecida Franco. Uma abordagem da história das instituições educacionais: a importância do arquivo escolar. Educação Unisinos, São Leopoldo, v. 11, n. 2, p. 85-90, maio/ago. 2007.

PERES, Eliane. A constituição de um arquivo e a escrita da história da educação: do gesto artesão à prática científica. Revista brasileira de história da educação, Campinas, n. 19, p. 219-241, 2019.

PORTAL DA EUDCAÇÃO - PRAIA GRANDE. Porto Aprendiz. Disponível em: http://www.praiagrande.sp.gov.br/administracao/Projeto_descricao.asp?cdSecretaria=50\&cdP rojeto $=69$. Acesso em: 10 nov. 2018.

SANTOS, Gabriela Cordeiro. A importância dos arquivos e museus escolares: o LIAME (Laboratório de Informação, Arquivo e Memória da Educação). 2018. 127f. Trabalho de Conclusão de Curso - Universidade Católica de Santos, Santos, 2018.

SÃO PAULO. Secretaria da Educação. Manual de trabalho em arquivos escolares. Elaboração 
de Teresa M. M. Baeza. São Paulo: CRE Mário Covas, IMESP, 2003.

SELLIS, Priscila. Praia Grande será $1^{\text {a }}$ Cidade do Estado a ter um Centro de Memória da Educação. $\quad 5 \quad$ set. $2012 . \quad$ Disponível http://www.praiagrande.sp.gov.br/pgnoticias/noticias/noticia_01.asp?cod=26556. Acesso em 10 nov. 2018.

VIDAL, Diana Gonçalves. História da Educação como Arqueologia: cultura material escolar e escolarização. Revista Linhas, Florianópolis, v. 18, n. 36, p. 251-272, jan./abr. 2017.

VIÑAO FRAGO, Antonio. Historia de la educación y historia cultural: possibilidades, problemas, cuestiones. Revista Brasileira de Educação, Rio de Janeiro, n. 0, p. 63-82, set./ dez. 1995.

Recebido em: 02 de dezembro de 2020. Aceito em: 30 de dezembro de 2020. 